\title{
Treatment of Anemia Progression via Magnetite and Folate Nanoparticles In Vivo
}

\author{
Hanaa Hussein Elsayed, ${ }^{1}$ Al Sayed A. M. Al-Sherbini, ${ }^{2}$ \\ Eman Elsayed Abd-Elhady, ${ }^{3}$ and Kawkab Abd El Aziz. Ahmed ${ }^{4}$ \\ ${ }^{1}$ Department of Nutrition Chemistry and Metabolism, National Nutrition Institute (NNI)-Healthy Minster, \\ 16 Kasr El Aini Street, Cairo 11441, Egypt \\ ${ }^{2}$ Department of Measurements, Photochemistry and Agriculture Applications, National Institute of Laser Enhanced Science (NILES), \\ Cairo University, Giza 11562, Egypt \\ ${ }^{3}$ Nutrition and Food Science Department, Faculty of Home Economics, Al-Azhar University, Cairo 11562, Egypt \\ ${ }^{4}$ Department of Pathology, Faculty of Veterinary Medicine, Cairo University, Giza 11562, Egypt
}

Correspondence should be addressed to Al Sayed A. M. Al-Sherbini; elsayed@niles.edu.eg

Received 21 October 2013; Accepted 9 January 2014; Published 4 March 2014

Academic Editors: Q. Chen, H. Duan, and K. H. Park

Copyright (C) 2014 Hanaa Hussein Elsayed et al. This is an open access article distributed under the Creative Commons Attribution License, which permits unrestricted use, distribution, and reproduction in any medium, provided the original work is properly cited.

Iron deficiency anemia is a major global public health problem. Food fortification with iron $(\mathrm{Fe})$ can be an effective strategy to control iron deficiency. An iron oxide nanoparticle (NP) is a new physical and chemical property form. These properties (small particle size, unique physical properties) make nanoiron a great scientific interest especially in the treatment of anemia. The study aimed to reduce anemia by nanoparticles (NPs). Forty-eight adult female Sprague-Dewily rats were divided into four groups (12 rats each). Group A represented a negative control. Other groups were fed standard diet iron free and three time of require zinc to reach anemic. Group B fed standard diet with ferrous sulfate until the improvement of the situation of anemia or for 8 weeks. Groups C and D were divided into three subgroups; each subgroup was fed a dose from magnetite or folate coated magnetite NPs. Results showed that symptoms of loss of appetite and severe lethargy demonstrate that magnetite and folate-coated magnetite nanoparticles have serious toxicological effects in vivo. Some doses from NPs improve blood picture during 2 weeks but change in histopathology examinations were occur in some groups within 2 weeks. Nanoparticles were considered the toxicological hazards especially the size of less than $54 \mathrm{~nm}$.

\section{Introduction}

Nanotechnologies enable scientists to manipulate matter at the nanoscale (one thousand millionth of a meter). Within this size-range, materials can exhibit new and unusual properties, such as altered chemical reactivity, or changed electronic, optical, or magnetic behavior [1].

Nanotechnology has also the potential to affect many aspects of food and agricultural systems. Food security, packaging materials, disease treatment, delivery systems, bioavailability, new tools for molecular and cellular biology, and new materials for pathogen detection are examples of the important items that are linked with nanotechnology within the food production chain $[2,3]$.
The term "nanofood" describes food which has been cultivated, produced, processed, or packaged using nanotechnology techniques or tools, or to which manufactured nanomaterials have been added [4]. Examples of nanoingredients and manufactured nanomaterial additives include nanoparticles of iron or zinc and nanocapsules containing ingredients like coenzyme Q10 or Omega 3.

Directive 2002/46/EC European Commission defined food supplements as concentrated sources of nutrients and other substances developed to supplement the normal diet and have nutritional or physiological effect whether used alone or combined. It is marketed in dose forms, namely, forms such as capsules, pastilles, tablets, pills, and other similar forms, sachets of powder, ampoules of liquid, drop 
suspending bottles, and other similar forms of liquids and powders designed to be taken in measured small unit quantities, such as nutrients, vitamins and minerals are meant.

Nanoparticles (NPs) can be more chemically reactive and more bioactive than larger particles. Because of their very small size, NPs also have much greater access to our bodies, so they are more likely than larger particles to enter cells, tissues, and organs. These novel properties offer many new opportunities for food industry applications, for example, as potent nutritional additives, stronger flavorings, and colorings, or antibacterial ingredients for food packaging. However, these same properties may also result in greater toxicity risks for human health and the environment [5].

Nanotechnologies may also present new risks because of their novel properties, as well as potential benefits to consumers. There is a wide variety of nanomaterials, and while many types of nanomaterials may well prove to be harmless, others may present a higher risk.

Iron-deficiency anemia is a common anemia (low red blood cell level) caused by insufficient dietary intake and absorption of iron and/or iron loss from intestinal bleeding, parasitic infection, menstruation, and so forth. Red blood cells contain iron, and they are not formed when iron is deficient [6].

The main criterion for diagnosing iron deficiency or iron deficiency anemia is that other causes of anemia have been ruled out, such as $B_{12} /$ folate deficiency (http://www .medicines.org.uk). Iron supplementation is indicated when diet alone cannot restore deficient iron levels to normal within an acceptable timeframe. Supplements are especially important when an individual is experiencing clinical symptoms of iron deficiency anemia. The goals of providing oral iron supplements are to supply sufficient iron to restore normal storage levels of iron and to replenish hemoglobin deficits [7].

Supplemental iron is available in two forms: ferrous and ferric. Ferrous iron salts (ferrous fumarate, ferrous sulfate, and ferrous gluconate) are the best-absorbed forms of iron supplements [8].

Nanoparticles (NPs) have emerged as a promising strategy for the efficient delivery of drugs used in the treatment of different types of diseases because of their many advantages over classical delivery matrices. The important technological advantages of nanoparticles used as drug carriers are high stability, high carrier capacity, feasibility of incorporation of both hydrophilic and hydrophobic substances, and feasibility of variable routes of administration, including oral application and inhalation. Nanoparticles (NPs), because of their small size, have distinct properties compared to the bulk form of the same material, thus offering many new developments in the fields of biosensors, biomedicine, and bionanotechnology. The adsorption of protein on NPs and its consequences on the structure and function are strongly dependent on the size and shape of the NPs [9].

Recent research on the gastrointestinal absorption of nanoparticles Hoffart et al. [10] has focused on enhancing the absorption of drugs, vaccines, and nutrients that either are degraded by the digestive process or poorly absorbed. Nel et al. [11] reported that there are toxicity concerns with nanoparticles. As most studies in this area have focused on airborne nanoparticles, there are only limited data on orally ingested trace element nanoparticles.

The focus in this semiexperimental research is to test the best absorbed forms of iron supplements (ferrous sulfate, magnetite, and folate coated magnetite) and to assess other effects from various doses and the best period for treatment.

\section{Materials and Methods}

2.1. Materials. All chemicals were of analytical reagent grade and were used without further purification. Nanostructured materials have been a subject of intensive research during the past 10 years $[12,13]$. The nanocomposite phases with the dimensions smaller than $100 \mathrm{~nm}$ exhibit extraordinary material characteristics, including mechanical, chemical, structural, optical, and electric/magnetic properties.

2.2. Nanomaterial. Preparation of magnetite and folatecoated magnetite: the photochemical method was carried out by dissolving the mixture of ferric oxalate with $\mathrm{FeCl}_{3} \cdot 6 \mathrm{H}_{2} \mathrm{O}$ in predetermined concentration ratio in $100 \mathrm{~mL}$ of aqueous hydrogen peroxide solution or $0.1 \mathrm{~mol} \mathrm{dm}-3$ folate aqueous hydrogen peroxide solution. The mixture was stirred in sunlight until the color changed. The $\mathrm{pH}$ of the solution was adjusted to 13 by addition of $1 \mathrm{~mol} \mathrm{dm}-3$ of $\mathrm{KOH}$ portionwise to the product. The black precipitates were collected by magnet and the product was washed several times with distilled water for several times and finally dried in the air.

2.3. Spectroscopic Characterization. Transmission electron microscopy of the produced samples was carried out by using Joel-100S transmission electron microscope, of resolution of $0.3 \mathrm{~nm}$. X-ray Diffract meter (Rigaku, Japan) performed crystallographic study on iron oxide powder. UV-Visble absorption spectra.

Figures 2(a) and 2(b) show that the absorption spectra of folic acid show two bands, the first one is at $\lambda_{\max }=366 \mathrm{~nm}$ and the other one pointed at $\lambda_{\max }=279 \mathrm{~nm}$ (Figure 2(a)). The absorption spectrum of folate attached magnetite nanoparticles shows the decreasing of the absorption bands for folic acid with another absorption band observed at $\lambda_{\max }=$ $339 \mathrm{~nm}$, (Figure 2(b)).

2.3.1. FTIR. The FTIR spectra of magnetite and folate coated magnetite were obtained as shown in Figures 2(a) and 2(b). For magnetite, the two strong absorption bands at around 633 and $562 \mathrm{~cm}^{-1}$ result from the split of the $\nu 1$ band at $570 \mathrm{~cm}^{-1}$, which corresponds to the $\mathrm{Fe}-\mathrm{O}$ bond of bulk magnetite. The band at $447 \mathrm{~cm}^{-1}$ comes from the shifting of the $v 2$ band of the $\mathrm{Fe}-\mathrm{O}$ bond of bulk magnetite at around $375 \mathrm{~cm}^{-1}$, (Figure 2(a)). The high frequency bands $\nu 1$ (Tetrahedral bands) and $\nu 2$ (Octahedral bands) are attributed to the vibrations of iron ions in both tetrahedral and octahedral positions, respectively. The surface groups of folic acid-modified magnetite are characterized by FTIR (Figure 2(b)). The absorption peaks at 596 and $445 \mathrm{~cm}^{-1}$ are attributed to $\mathrm{Fe}-\mathrm{O}$ bond absorption. The absorption peak at $1643 \mathrm{~cm}^{-1}$ can be 


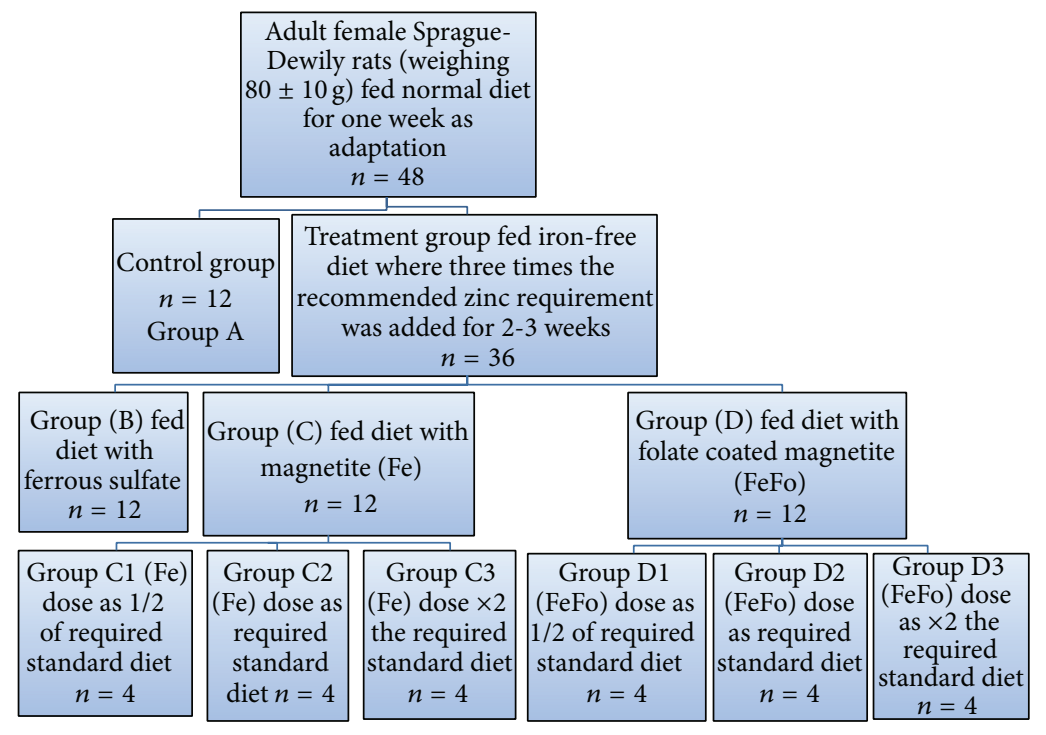

FIgURE 1: Experimental design.

attributed to $\mathrm{N}-\mathrm{H}$ bending vibration, which is also favorable evidence for the existence of primary amine in molecules. Absorption at $1604 \mathrm{~cm}^{-1}$ corresponded to the aromatic ring stretching vibration in the folic acid molecule, absorption at $1396 \mathrm{~cm}^{-1}$ corresponded to the benzoic vibrations in folic acid molecule, and absorption at $1533 \mathrm{~cm}^{-1}$ can be attributed to the characteristic absorption of amide. Infrared data proved that folic acid molecules have successfully modified the surface of $\mathrm{Fe}_{3} \mathrm{O}_{4}$ nanoparticles.

2.4. Animals. Forty-eight adult female Sprague-Dewily rats (weighing $80 \pm 10 \mathrm{~g}$ ) were obtained from Vaccine and Immunity Organization, Hellwan farm, Cairo, Egypt. Rats were housed individually in stainless steel cages with grated stainless steel floors under healthy environmental conditions. Rats consumed deionized water and diet ad-libitum. Nanoiron was applied at three doses $(87,174$, and $348 \mathrm{mg} / \mathrm{kg}$ diet). Nanoiron plus folate was at 87.3, 174.5, and $349 \mathrm{mg} / \mathrm{kg}$ diet according to Reeves et al., [14]. These doses represented 1/2 the requirement and two-time from the requirement daily intake of iron in standard diet.

2.5. Chemicals and Other Materials. Casein "> $>85 \%$ protein," corn starch, DL-methionine, choline chloride, vitamins, minerals, and other required chemicals obtained from ElGomhorya Company for Chemicals and Drugs, Cairo, Egypt.

2.6. Standard Diet. Standard diet was prepared from fine ingredients per $100 \mathrm{~g}$. The diet had the following composition.

Sunflower oil $10 \%$, salt mixture $4 \%$ [15], vitamin mixture $1 \%$ [16], choline chloride $0.2 \%$, protein $12 \%$, DL-methionine $0.3 \%$, and corn starch up to $100 \mathrm{~g}$ according to Reeves et al. [14].

2.7. Experimental Design in Figure 1. Rats were divided into four groups (12 rats each). Group A $(n=12)$ that served as negative control was anesthetized and sacrificed. Blood samples were taken from hepatic portal vein in heparinized tube to analysis blood picture. Liver, spleen, and lungs were isolated immediately, plotted free from adhering blood, washed with cooled saline ( $0.9 \%$ sodium chloride/deionized water), and dried between filter paper. All organs were weighed and then put in $10 \%$ formalin until further histopathology examination. The other 36 rats were fed ironfree diet where three times the recommended zinc requirement was added to rats' diet to get anemic.

Anemic rats were divided into three groups. Group B $(n=12)$ was fed standard diet with iron as ferrous sulfate until treated from anemia. Group $\mathrm{C}$ was divided into three subgroups; (four rats each) fed basal diet with three doses of magnetite. In addition, group $\mathrm{D}(n=12)$ was fed standard diet with three doses of folate coated magnetite for the treatment of anemia. Every week, blood was collected from eye vein of each rat to assess blood picture. Blood treated with heparin was used for analyzing hematologic parameters such as erythrocyte count (red blood cell [RBC]), hemoglobin (Hb), hematocrit (Hct), mean corpuscular volume (MCV), mean corpuscular hemoglobin $(\mathrm{MCH})$, mean corpuscular hemoglobin concentration (MCHC), platelet (PLT) count, and total leucocyte count (white blood cell [WBC]) were determined on day 14 and every week for 8 weeks or for treatment of anemia.

After reaching the normal level of hemoglobin, rats were anesthetized and sacrificed; all organs were weighed and put in $10 \%$ formalin until further histopathology examination. Body weights of rats were recorded twice a week to monitor percentage body weight change as follows.

(i) Blood picture analysis was done by using blood cell counter "GRMA-210."

(ii) \% Body weight change was calculated as Final body weight - Initial body weight/Initial body weight $\times 100$.

(iii) Relative weight of organs was calculated as organ weight/final body weight. 

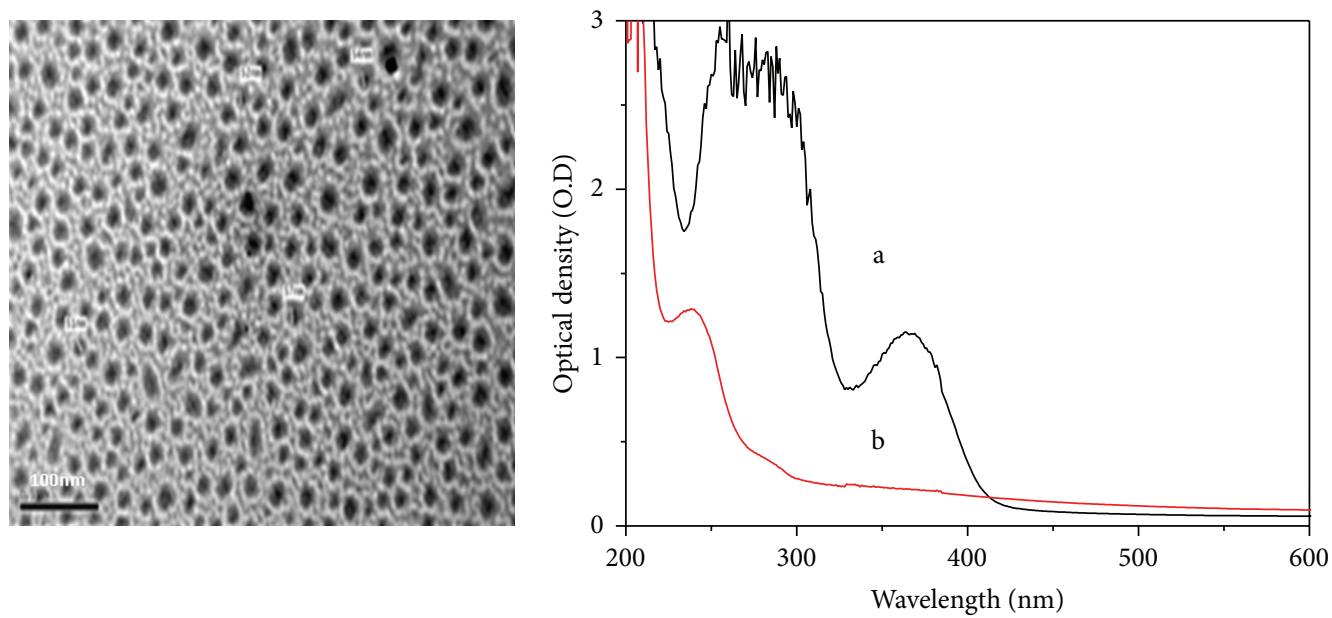

(a)

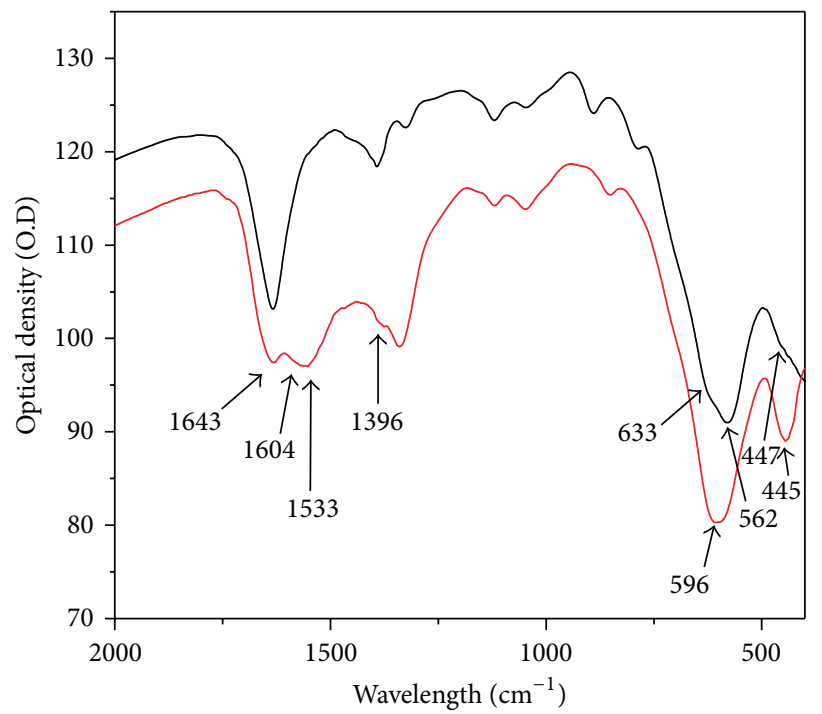

(b)

FIGURE 2: Absorption spectra of (a) aqueous solution of folic acid and (b) colloidal solution of foliate coated SPIO nanoparticles.

2.8. Histopathology Examination. Tissue samples (liver, kidneys, spleen, and lung) were fixed in neural buffered formalin $10 \%$, dehydrated in ascending concentrations of ethanol, cleaned in xylene, and embedded in paraffin. Sections 4-5 $\mu$ thick were prepared and stained with Hematoxylin and Eosin [17].

2.9. Statistical Analysis. All data are presented as mean \pm SE. Differences between groups means were assessed by an unpaired Student's $t$-test for single comparisons or by ANOVA for multiple comparisons using SPSS 16.0. Values of $P<0.05$ were considered significant.

\section{Results}

\subsection{Characterization of Material Nanoparticles (MNPs)}

3.1.1. Transmission Electron Micrograph (TEM). Transmission electron microscopy for the prepared SPIO NPs showed that particles have approximately $(\sim)$ spherical shapes and their sizes were in the range of $\sim 54 \pm 3 \mathrm{~nm}$, using UV/VIS spectroscopic characterization (Figure 2(a)).

3.1.2. X-Ray Diffraction Analysis. The XRD spectrum of the prepared SPIO nanoparticles shows that six characteristic peaks for $\mathrm{Fe}_{3} \mathrm{O}_{4}(2 \theta=30.10,35.50,43.10,53.40,57.00$, and $62.60)$, marked by their indices $220,311,400,422,511$, and 440, were observed for all samples using FTIR spectroscopic characterization (Figure 2(b)).

3.2. Biology Results. No animal mortality was found in rats treated with various iron-supplemented dietsbut there were some symptoms such as loss of appetite and severe lethargy which were observed during the experimental period of the rat, after administration of nanoparticle suspension. Results presented in Table 1 indicated that the body weights change and different relative weight rats received iron-supplemented diets. Results showed that the relative weight liver of group 
TABLE 1: Relative weight and body weight change.

\begin{tabular}{|c|c|c|c|c|c|}
\hline & Relative wt. liver & Relative wt. spleen & Relative wt. lung & Relative wt. renal & Body weight change $\%$ \\
\hline Normal G (A) & $3.5 \pm 0.07$ & $0.27 \pm 0.09$ & $0.54 \pm 0.08$ & $0.81 \pm 0.08$ & $17.3 \pm 3.5$ \\
\hline $\mathrm{FeSO}_{4}$ G (B) & $4.01 \pm 0.2$ & $0.41 \pm 0.04$ & $0.76 \pm 0.09$ & $0.77 \pm 0.09$ & $11.0 \pm 4.5$ \\
\hline $\mathrm{Fe} \mathrm{G}(\mathrm{Cl})$ & $4.1 \pm 0.5$ & $0.47 \pm 0.08$ & $0.68 \pm 0.06$ & $0.87 \pm 0.06$ & $24.0 \pm 5.7$ \\
\hline $\mathrm{Fe}$ G (C2) & $4.3 \pm 0.5$ & $0.5 \pm 0.07$ & $0.85 \pm 0.09$ & $0.79 \pm 0.02$ & $20.3 \pm 6.6$ \\
\hline $\mathrm{Fe} \mathrm{G}(\mathrm{C} 3)$ & $4.63 \pm 0.5$ & $0.63 \pm 0.1$ & $0.93 \pm 0.08$ & $0.81 \pm 0.09$ & $9.3 \pm 5.4$ \\
\hline $\mathrm{Fe}+\mathrm{Fo} G(\mathrm{D} 1)$ & $3.98 \pm 0.2$ & $0.44 \pm 0.03$ & $0.86 \pm 0.1$ & $0.84 \pm 0.1$ & $19.5 \pm 7.5$ \\
\hline $\mathrm{Fe}+\mathrm{Fo} G(\mathrm{D} 2)$ & $3.93 \pm 0.2$ & $0.47 \pm 0.05$ & $0.79 \pm 0.2$ & $0.91 \pm 0.3$ & $7.7 \pm 1.1$ \\
\hline $\mathrm{Fe}+\mathrm{Fo} G(\mathrm{D} 3)$ & $4.48 \pm 0.1$ & $0.54 \pm 0.02$ & $0.59 \pm 0.02$ & $0.80 \pm 0.04$ & $18.5 \pm 8.8$ \\
\hline
\end{tabular}

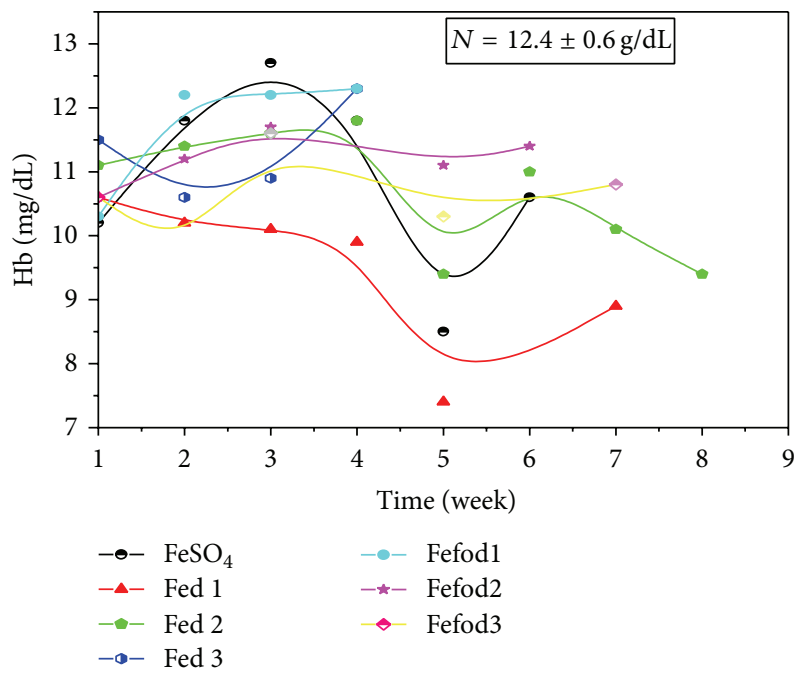

Figure 3: Hemoglobin $(\mathrm{Hb})$ level in rat blood fed different diet with or without nanoparticles. $N=$ Normal level.

(D2) was the nearest to normal group. The highest relative weights of lung and spleen were in group (C3) but they were similar to normal group in relative weight renal. The highest percent of body weight change was in the group fed first dose of magnetite while the lowest percent showed in group (D2).

\subsection{Biochemical Results}

3.3.1. Hematology. Dietary iron deficiency with adding twotimes zinc requirement for 2 to 3 weeks led to nutritional iron deficiency anemia in rats.

Results presented in Figures 3 and 4 indicated that the $\mathrm{Hb}$ and Hct were corrected in $75 \%$ of rats fed ferrous sulfate (Group B) during three weeks, while 25\% fluctuated between up and down in the following weeks failing to reach normal value. Group $\mathrm{C} 1$ rats treated with $1 / 2$ iron requirement dose from magnetite showed gradual decrease in Hb level throughout most of the follow-up weeks and were sacrificed at 7 weeks without showing improvement in iron status. Rats in Groups C2 and C3 reached normal $\mathrm{Hb}$ and Hct values by the 4 th week followed by marked decreased $\mathrm{Hb}$ and $\mathrm{Hct}$ values afterwards.

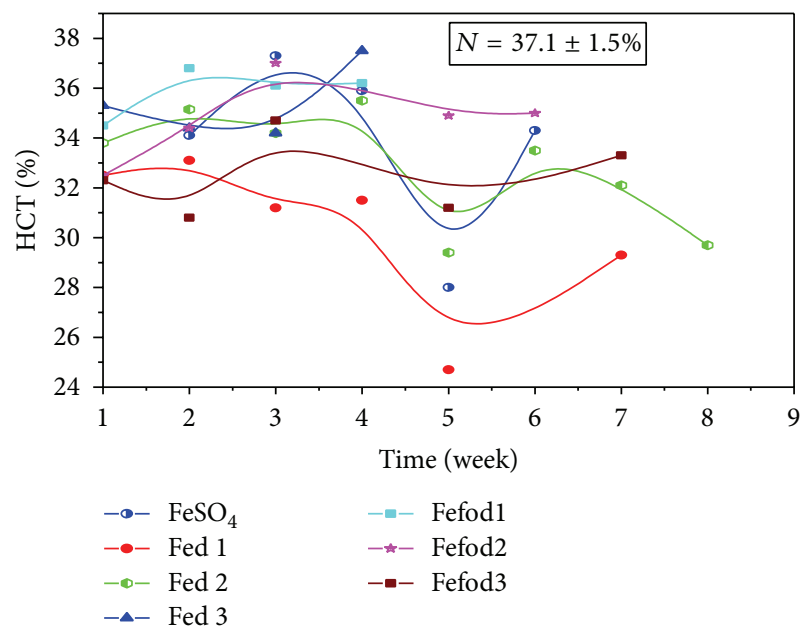

FIGURE 4: Hematocrit (HCT) level in rat blood fed different diet with or without nanoparticles. $N=$ Normal level.

On the other hand, Group D1 (recipient of 1/2 dose of iron requirements and folat) reached normal $\mathrm{Hb}$ and $\mathrm{Hct}$ levels within four weeks. The other two Groups D2 and D3 showed improvement in $\mathrm{Hb}$ and Hct level within three weeks followed by decline in $\mathrm{Hb}$ and Hct values.

Figures 5, 6, 7, and 8 demonstrated normal values of $\mathrm{RBCs}, \mathrm{MCV}, \mathrm{MCH}$, and $\mathrm{MCHC}$ within 3 weeks in Group $\mathrm{B}$ reaching plateau afterwards. Group D2 did not show any improvement in RBC level for the duration of the study. All groups exceeded normal values at different speeds or durations.

The rats fed 1st dose of magnetite and 3rd dose of folatecoated magnetite the results of $\mathrm{MCV}$ were less than normal volume to $7 \mathrm{wk}$. while the 2 nd dose of magnetite showed that the normal dose fruition at $4 \mathrm{wk}$. after that increased about normal level. The rats received the $3 \mathrm{rd}$ dose of iron nanoparticles treated at two weeks and then the results fluctuated between up and down. The 1st dose of folate-coated magnetite indicated that normal level was at 5 weeks.

$\mathrm{MCH}$ was less than normal level among all treatment groups, showed in Figure 6.

A bell shaped curve of MCHC parameter was noticed in Groups B, C2, D1, and D3 around the third week. 


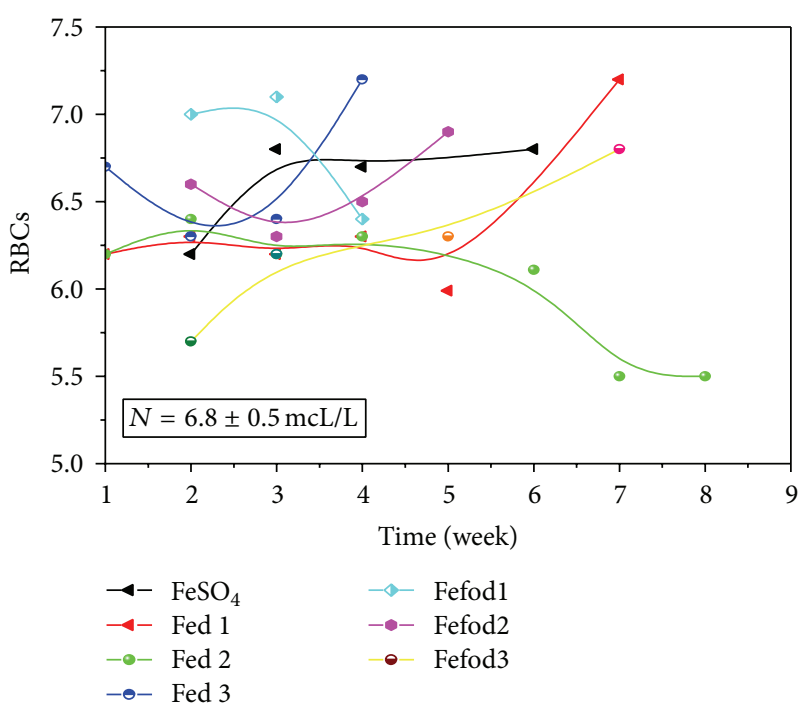

FIGURE 5: Red blood cells (RBCs) level in rat blood fed different diet with or without nanoparticles. $N=$ Normal level.

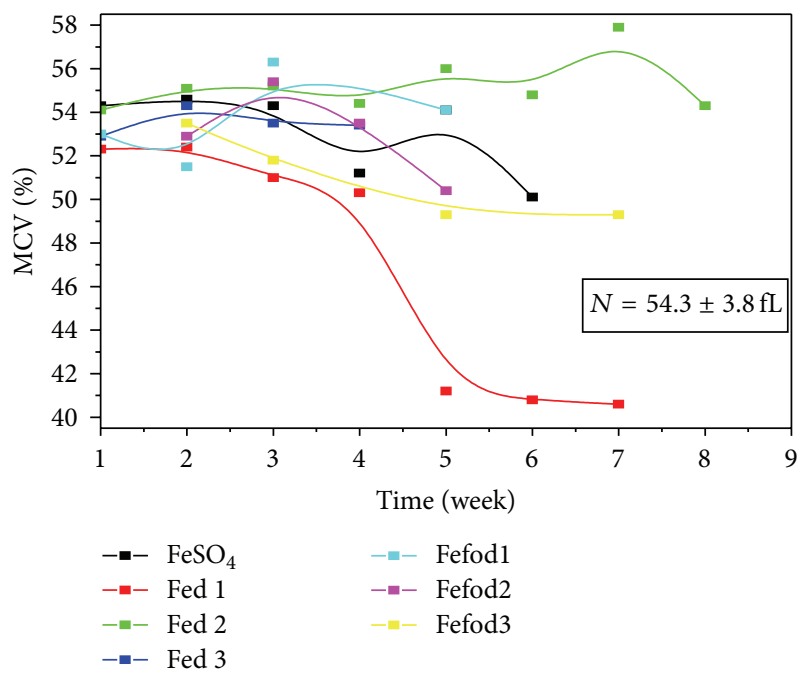

Figure 6: Mean corpuscular volume (MCV) in rat blood fed different diet with or without nanoparticles. $N=$ Normal level.

Platelets level explained that increased in-group fed ferrous sulfate at third wk. after that decreased level in same group. Steady raise of PLT level until 5th week in group fed 1st dose of magnetite. Level of PLT increased from 3rd to 4th week, and then decreased from 5th to 7 th week, but at eighth week, the increase was more than normal level of group fed 2nd dose from magnetite. Steady increase in group that received 3 rd dose of magnetite. The 1st dose added to diet of folate-coated magnetite clarified that increased in PLT level at 2 nd wk. and decreased after that but it steal higher than normal value. Rats fed 2nd and 3rd doses of folate-coated magnetite showed that the level of PLT fluctuated between up and down.

MPV \% demonstrated that the normal level was at the 3rd week with group fed 1st dose of magnetite and ferrous sulfate

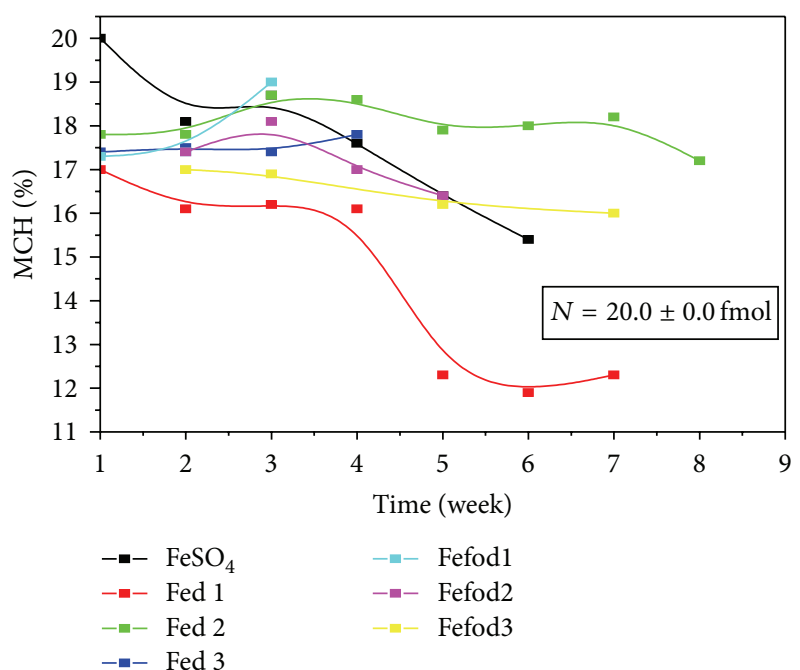

FIGURE 7: Mean corpuscular hemoglobin $(\mathrm{MCH})$ in rat blood fed different diet with or without nanoparticles. $N=$ Normal level.

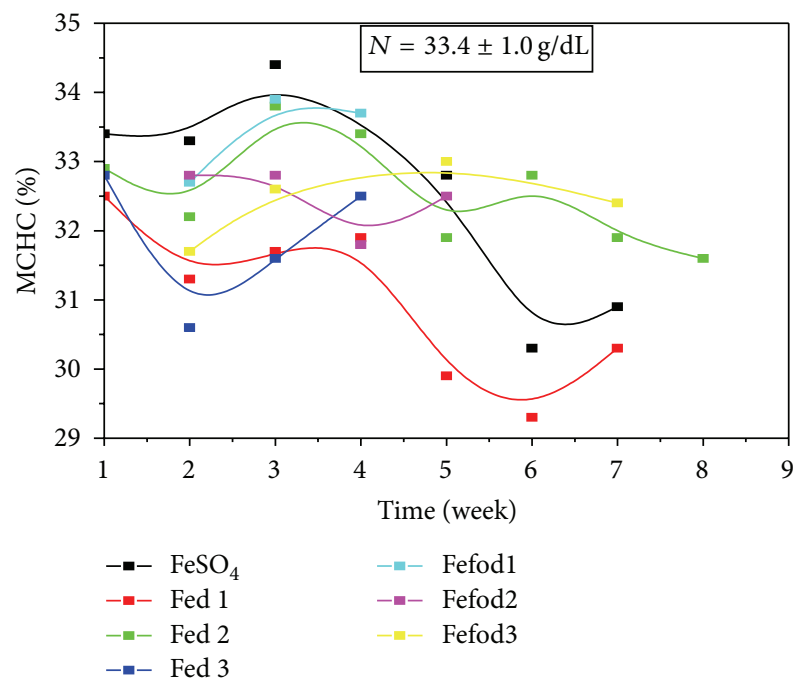

FIGURE 8: Mean corpuscular hemoglobin concentration (MCHC) in rat blood fed different diet with or without nanoparticles. $N=$ Normal level.

but the 2nd and 3rd doses of magnetite and 1st dose of folatecoated magnetite showed the normality at 2 week, while the 2nd and 3rd doses of folate-coated magnetite increased more than normal and after that decreased less than normal.

Figures 11 and 12 displayed that treated groups with nanomaterial the result fluctuated between increase and decrease than normal level of WBC. The largest increase shows in the group fed the 2nd dose of folate-coated magnetite.

Lymph finding showed that all group fluctuated between increase and decrease than normal level (Figure 12).

\subsection{Histopathology Results}

3.4.1. Liver. Microscopically, examined sections of liver from rat treated with magnetite (1st dose) revealed cytoplasmic 


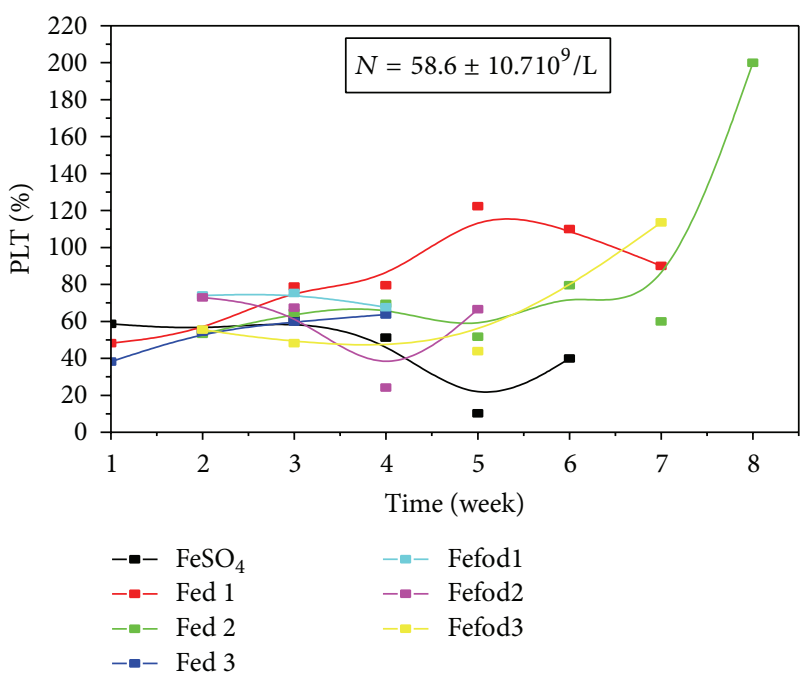

Figure 9: Platelets level (PLT) in rat blood fed different diet with or without nanoparticles. $N=$ Normal level.

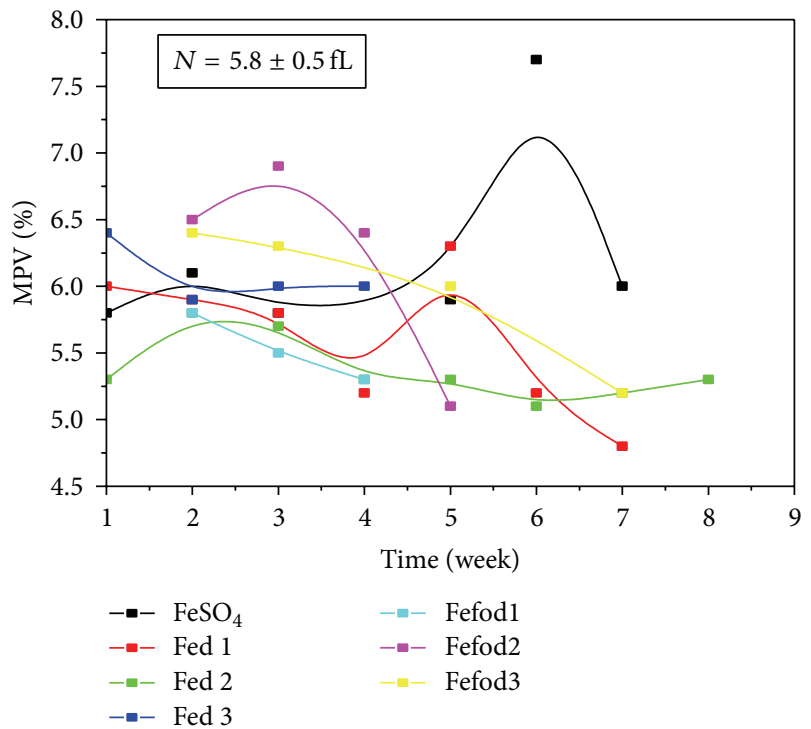

Figure 10: Mean Platelets volume (MPV) in rat blood fed different diet with or without nanoparticles. $N=$ Normal level.

vacuolizations of hepatocytes, infiltration of centrolobular hepatocytes with leucocytic inflammatory cells (Figure 13), sinusoidal leukocytosis (Figure 14) and portal infiltration with leucocytes. Moreover, at the 2nd dose and 3rd dose, examined liver revealed Kupffer cells activation, focal hepatic necrosis associated with leucocytic cells infiltration (Figure 15) cytoplasmic vacuolizations of hepatocytes, apoptosis of hepatocytes (Figure 16), as well as portal infiltration with leucocytes. Liver sections of rat treated with both magnetite and folate coated magnetite (1st and 2nd doses) showed Kupffer cells activation, cytoplasmic vacuolization of hepatocytes and focal hepatic necrosis associated with leucocytic cells infiltration (Figure 17). At the 3rd dose, in addition to the previously mentioned changes, examined sections

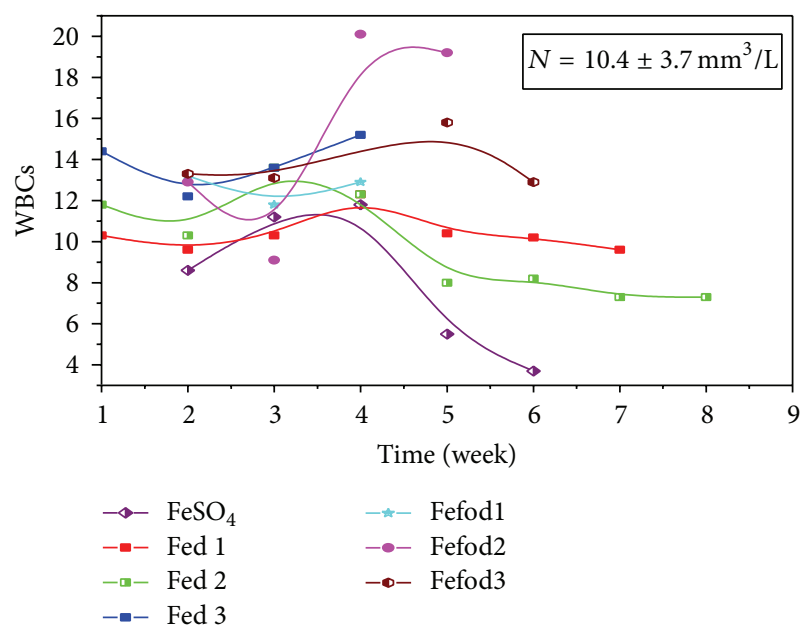

FIGURE 11: White blood cells level (WBCs) in rat blood fed different diet with or without nanoparticles. $N=$ Normal level.

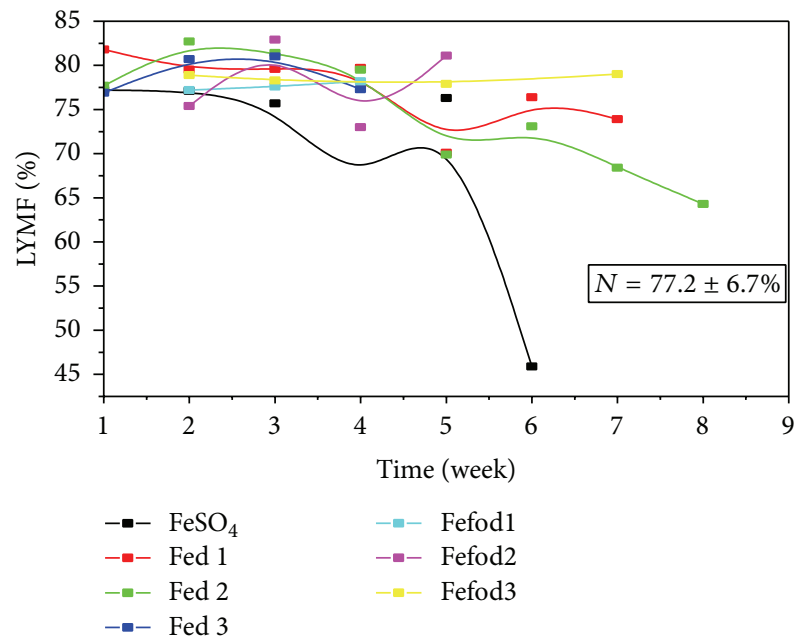

FIGURE 12: Lymph level in rat blood fed different diet with or without nanoparticles. $N=$ Normal level.

revealed apoptosis of hepatocytes. Examined sections of liver from rats either treated with sulphate or control, untreated rat revealed no histopathological changes (Figure 18).

3.4.2. Kidneys. Microscopically, examined sections of kidneys of rat treated with magnetite (1st $2 \mathrm{nd}$, and 3rd doses) revealed the same histopathological alterations which summarized as vacuolations of epithelial lining renal tubules as well as endothelial lining glomerular tufts (Figure 19), focal tubular necrosis associated with leucocytic inflammatory cells infiltration (Figure 20), and tubular necrosis associated with calcification (Figure 21). Improvement in the histopathological picture was noticed in examined sections of rat treated with both folate coated magnetite. At the 1st dose, examined sections showed vacuolations of epithelial lining renal tubules and endothelial lining glomerular tufts together with focal tubular necrosis associated with leucocytic cells infiltration (Figure 22). Meanwhile, at 2nd and 3rd doses, 


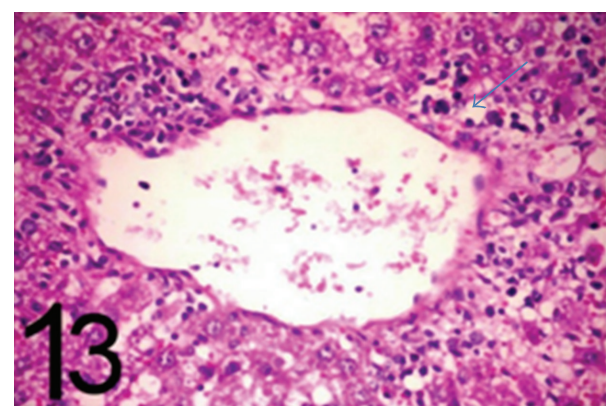

FIGURE 13: Liver of rat treated with nanoiron (1st dose) showing cytoplasmic vacuolizations of hepatocytes, infiltration of centrilobular hepatocytes with leucocytic inflammatory cells ( $\mathrm{H} \& \mathrm{E} \times 400)$.

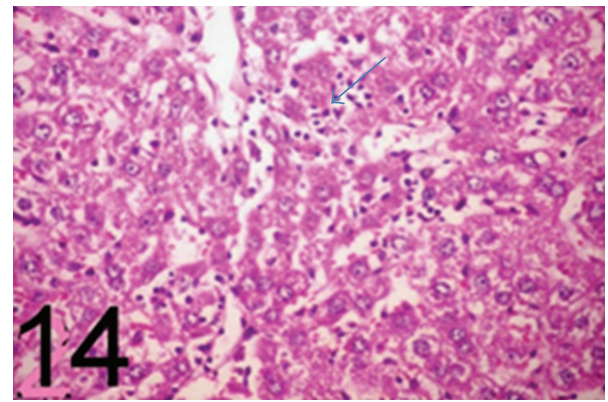

FIGURE 14: Liver of rat treated with nanoiron (1st dose) showing sinusoidal leukocytosis $(\mathrm{H} \& \mathrm{E} \times 400)$.

kidneys sections revealed vacuolations of epithelial lining renal tubules as well as endothelial lining glomerular tufts (Figure 23). However, examined sections either treated with sulphate or control, untreated rat revealed no histopathological changes (Figure 24).

3.4.3. Lung. Histopathology, examined sections of lung of rat treated with magnetite (1st, 2 nd, and 3rd doses) revealed hyperplasia of bronchial epithelium with intraluminal accumulation of mucous exudate (Figure 25), interstitial pneumonia (Figure 26), perivasculitis (Figure 27), and hyperplasia of peribronchial lymphocytes. Improvement in the histopathological picture was observed in examined sections from rat treated with both nanoiron and folic acid. Examined lung (1st, 2nd, and 3rd doses) revealed a slight thickening of interstitial tissue (Figure 28) and perivasculitis (Figure 29). However, examined sections either treated with sulphate or control, untreated rat revealed no histopathological changes (Figure 30).

3.4.4. Spleen. Microscopically, examined sections of spleen of rat treated with magnetite (1st, 2 nd, and 3rd doses) revealed lymphocytic necrosis and depletion (Figure 31). Meanwhile, examined spleen of rats treated with folate coated magnetite or treated with sulphate or those from control, untreated group revealed no histopathology changes (Figure 32).

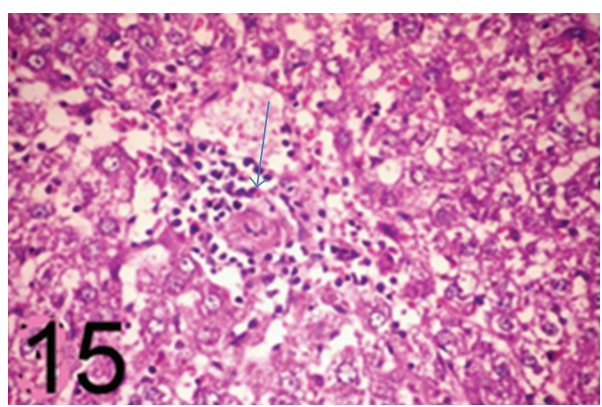

FIGURE 15: Liver of rat treated with nanoiron (2nd dose) showing focal hepatic necrosis associated with leucocytic cells infiltration $(\mathrm{H}$ $\& \mathrm{E} \times 400)$.

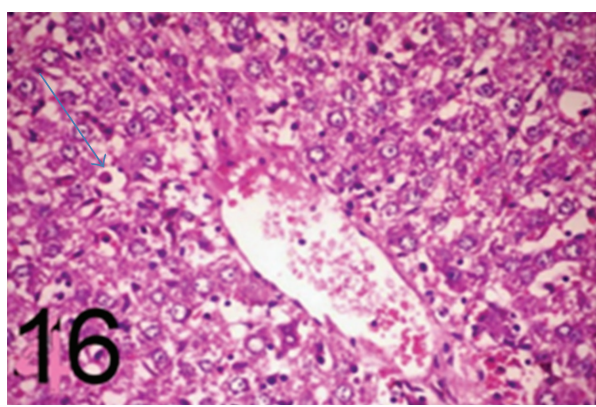

FIGURE 16: Liver of rat treated with nanoiron (3rd dose) showing Kupffer cells activation, cytoplasmic vacuolizations of hepatocytes, and apoptosis of hepatocytes $(\mathrm{H} \& \mathrm{E} \times 400)$.

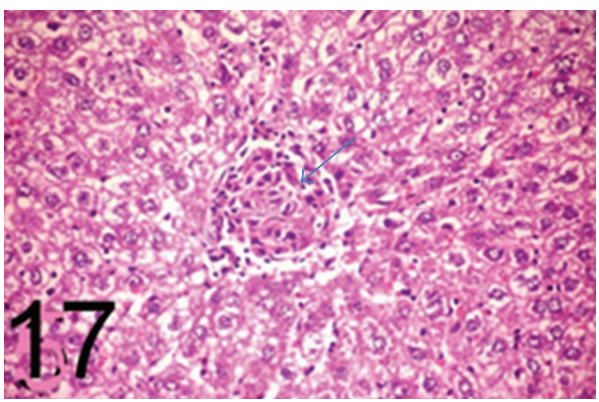

FIGURE 17: Liver of rat treated with nanoiron and folic acid (1st dose) showing cytoplasmic vacuolizations of hepatocytes and focal hepatic necrosis associated with leucocytes infiltration $(\mathrm{H} \& \mathrm{E} \times 400)$.

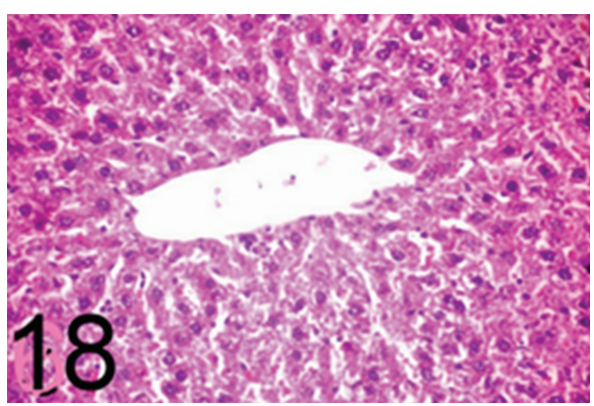

FIGURE 18: Liver of rat treated with sulphate showing no histopathological changes $(\mathrm{H} \& \mathrm{E} \times 400)$. 


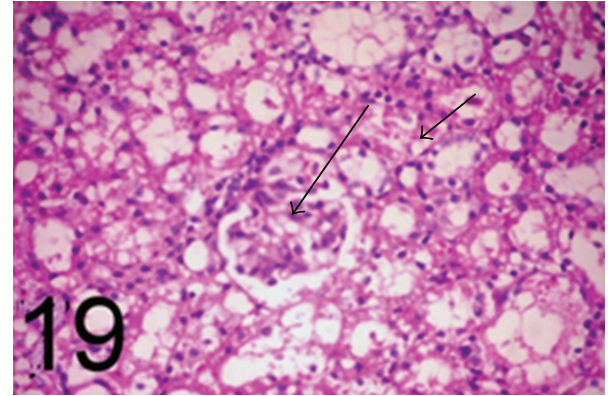

FIGURE 19: Kidneys of rat treated with nanoiron (1st dose) showing vacuolations of epithelial lining renal tubules as well as endothelial lining glomerular tufts $(\mathrm{H} \& \mathrm{E} \times 400)$.

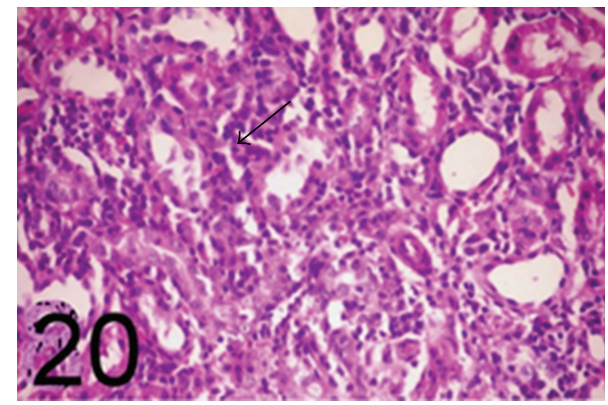

Figure 20: Kidneys of rat treated with nanoiron (1st dose) showing focal tubular necrosis associated with leucocytic inflammatory cells infiltration $(\mathrm{H} \& \mathrm{E} \times 400)$.

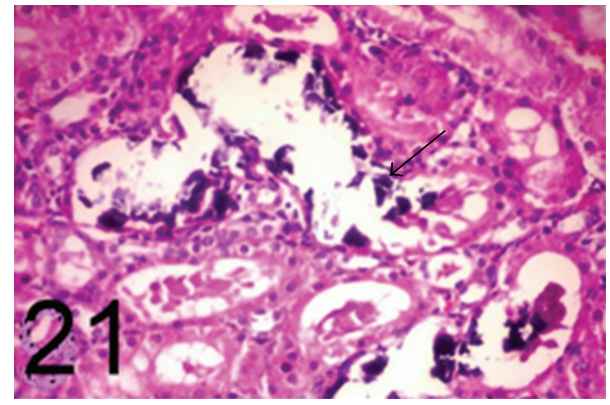

FIGURE 21: Kidneys of rat treated with nanoiron (3rd dose) showing tubular necrosis associated with calcification $(\mathrm{H} \& \mathrm{E} \times 400)$.

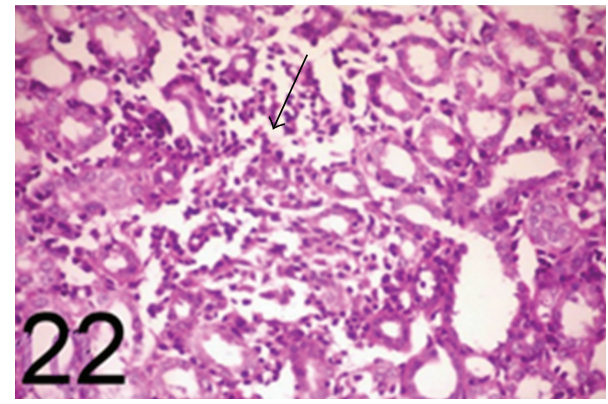

Figure 22: Kidneys of rat treated with nanoiron and folic acid (1st dose) showing focal necrosis of renal tubules associated with leucocytic cells infiltration $(\mathrm{H} \& \mathrm{E} \times 400)$.

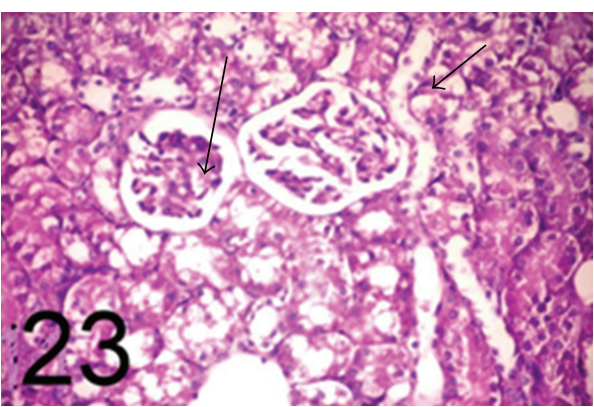

FIGURE 23: Kidneys of rat treated with nanoiron and folic acid (2nd dose) showing vacuolations of epithelial lining renal tubules as well as endothelial lining glomerular tufts $(\mathrm{H} \& \mathrm{E} \times 400)$.

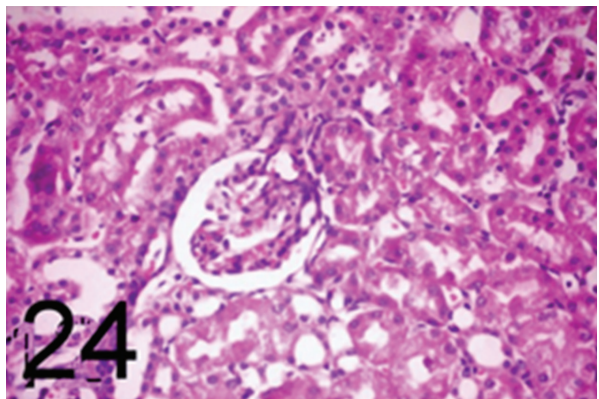

FIGURE 24: Kidneys of rat treated with sulphate showing no histopathological changes $(\mathrm{H} \& \mathrm{E} \times 400)$.

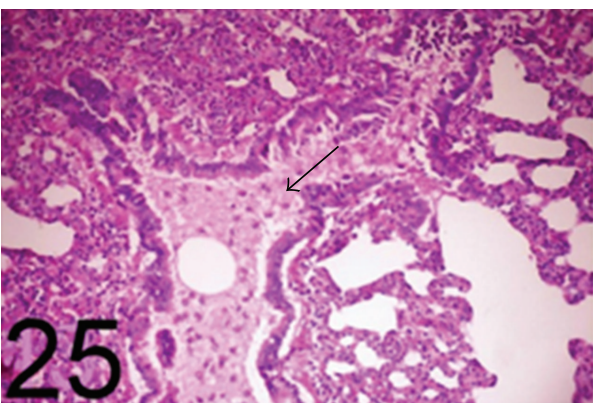

FIGURE 25: Lung of rat treated with nanoiron (1st dose) showing hyperplasia of bronchial epithelium with intraluminal accumulation of mucous exudate $(\mathrm{H} \& \mathrm{E} \times 200)$.

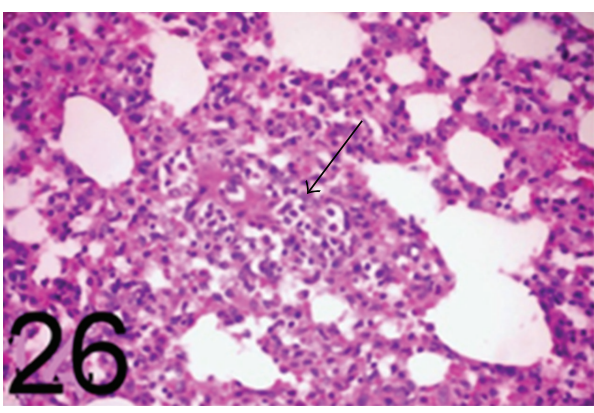

FIGURE 26: Lung of rat treated with nanoiron (1st dose) showing interstitial pneumonia (H \& E X 400). 


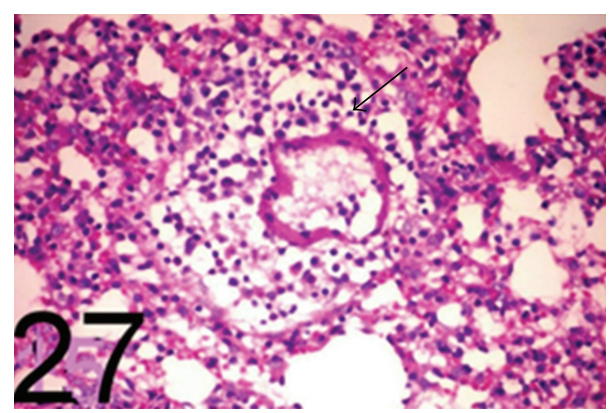

Figure 27: Lung of rat treated with nanoiron (2nd dose) showing perivasculitis $(\mathrm{H} \& \mathrm{E} \times 400)$.

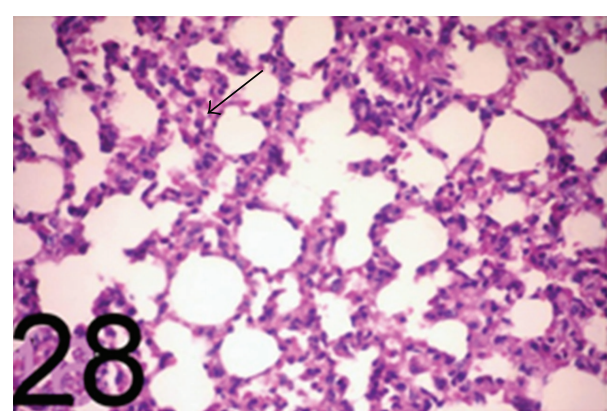

FIGURE 28: Lung of rat treated with nanoiron and folic acid (1st dose) showing slight thickening of interstitial tissue $(\mathrm{H} \& \mathrm{E} \times 400)$.

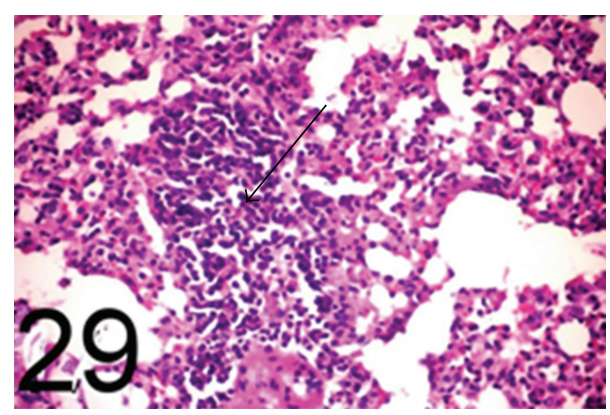

FIGURE 29: Lung of rat treated with nanoiron and folic acid (3rd dose) showing perivasculitis $(\mathrm{H} \& \mathrm{E} \times 400)$.

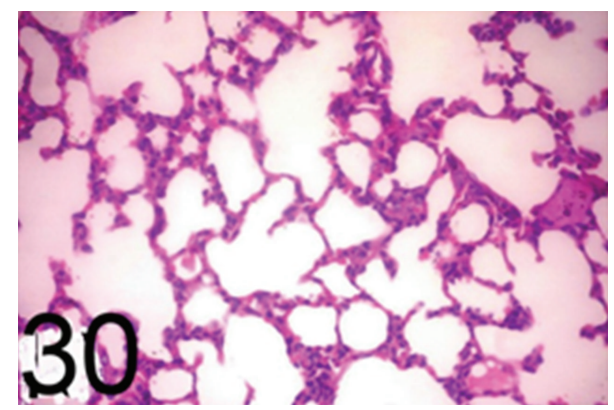

FIGURE 30: Lung of rat treated with sulphate showing no histopathological changes $(\mathrm{H} \& \mathrm{E} \times 400)$.

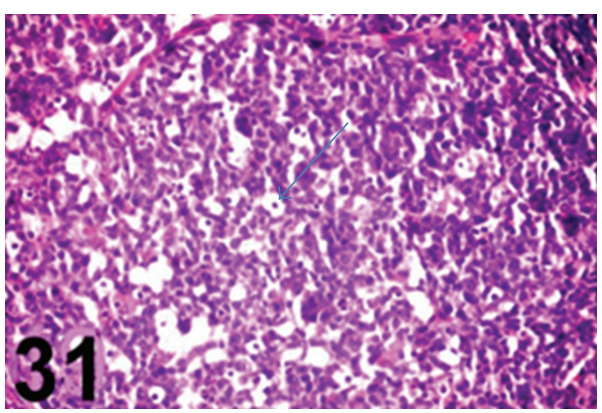

FIgURE 31: Spleen of rat treated with nanoiron (2nd dose) showing lymphocytic necrosis and depletion $(\mathrm{H} \& \mathrm{E} \times 400)$.

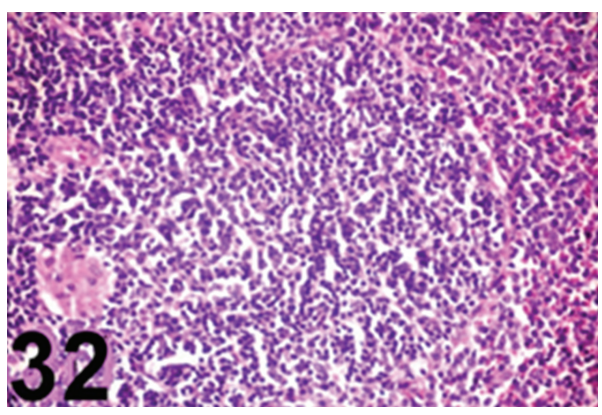

FIGURE 32: Spleen of rat treated with nanoiron and folic acid (2nd dose) showing no histopathological changes (H \& E $\times 400)$.

\section{Discussion}

4.1. Hematology. Findings of current study in Figures 3 and 4 are consistent with previous reports. Singh [18] who illustrated that generally the internalization of NPs within cells is likely to occur in a time-dependent manner followed by plateau when cells reach maximum saturation. Similarly, Fischer et al. [19] reported that cell viability subsequent to nanoparticle uptake is expected to be either unaffected or decreased as a function of time. The transient cell growth and proliferation observed in the study may be due to additional nutrients present within the cells in the form of iron and phospholipids for the viable cells stimulating cell growth. Soenen et al. [20] explained the bell-shaped curve observed as an initial lag phase in cellular activity where the cells have to deal with sudden exposure and internalization of NPs, middle $\log$ phase marked by a period $(6-10 \mathrm{~h})$ of cellular growth as the cells resume their cellular activities, and finally the cell number either stabilizes or there is reduced cell viability as a result of cell toxicity.

Regarding Figure 5, among the causes of low RBC are the nutritional deficiency, bone marrow disorders or damage, chronic inflammatory disease, and kidney failure. On the other hand, high RBC level also known as polycythemia could be caused by dehydration, lung (pulmonary) disease, kidney, or other tumor that produces excess erythropoietin [21].

With regard to MCV value in Figure 6, low results of MCV indicate that RBCs are smaller than normal (microcytic), caused by iron deficiency anemia or thalassemia, but the high findings indicated that RBCs are larger than normal 
(macrocytic), for example, in anemia caused by vitamin B12 or folate deficiency [21].

The low results of MCH illustrate mirrors MCV results; small red cells would have a lower normal value [21].

The low concentration may be low when MCV is low; decreased MCHC values (hypochromia) are seen in conditions such as iron deficiency anemia but high concentration, increased MCHC values (hyperchromia) are seen in conditions where the hemoglobin is more concentrated inside the red cells [21]. However, the criteria to define toxicity of NPs needs to be clearly defined [22], particularly as emerging studies have begun to highlight aberrant cellular responses including DNA damage, oxidative stress, and mitochondrial membrane Dysfunction.

Results showed that the level of PLT fluctuated between up and down for all treated groups that were demonstrated in Figure 9. Low result is known as thrombocytopenia (viral infection, platelet autoantibody, cirrhosis). Causes of high result are known as thrombocytosis (cancer (lung, gastrointestinal, breast, ovarian, and lymphoma), iron deficiency anemia, and hemolytic anemia). Sadeghiani et al. [23] showed that uncoated iron oxide NPs have very low solubility that can lead to precipitation (if not sufficiently small) due to gravitation forces and also a high rate of agglomeration under physiological conditions that can impede blood vessels particularly in a clinical exposure setting. Vieira et al. [24] study the Fe3O4 NPs that could potentially be used as novel therapeutic agents in the treatment of protein myeloid aggregation-associated human pathologies.

Figure 10 illustrated MPV \% in all rats groups. Causes of low value of MPV indicate that average size of platelets is small and a low MPV may mean that a condition is affecting the production of platelets by the bone marrow. Causes of high result indicate a high number of larger, younger platelets in the blood; this may be due to the bone marrow producing and releasing platelets rapidly into circulation [21].

Figure 11 showed WBC results of normal and treatment group. Low result of WBC level is known as neutropenia (reaction to drugs, chemotherapy, bone marrow damage, and cancer that spreads to the bone marrow). Causes of high result are known as neutrophilia (acute bacterial infections, inflammation, and tissue death [21]).

Result of lymph showed in Figure 12. Low result of lymph is known as lymphocytopenia (autoimmune disorders, infections, and bone marrow damage). Causes of high result are Known as lymphocytosis (acute viral infections, certain bacterial infections, toxoplasmosis, and chronic inflammatory disorder) [21]. Häfeli et al. [25] reported that exposure to nanoparticles (NPs) has been associated with significant toxic effects such as inflammation, impaired mitochondrial function (MTT), membrane leakage of lactate dehydrogenase (LDH assay), and generation of reactive oxygen species (ROS). Singh [19] showed that the exposure to these NPs and the effect that the range of surface coatings utilized for functionality are crucial. Therefore, there is a considerable need to address biocompatibility and biosafety concerns associated with their usage in a variety of applications. Buscombe et al. [26] explanation that the sentinel lymph node (SLN) is defined as the first regional lymph node receiving lymphatic drainage from a malignant tumor and the first node to which metastatic cells are likely to anchor. Therefore, accurate detection and characterization of the SLN is of major importance for cancer staging and for the choice of therapy in patients.

\subsection{Histopathology}

4.2.1. Liver. Findings showed in Figures from 13 to 18 agree with some studies on nanoparticles. Increasing numbers of studies demonstrated that many types of nanoparticles have toxic effects mainly on liver, kidneys, and spleen tissues [27]. In liver tissue, the hydropic degeneration around the central vein was prominent and the spotty necrosis of hepatocyte was also found in the female mice postexposure 2 weeks to the $80 \mathrm{~nm}$ and fine $\mathrm{TiO}_{2}$ particles. Pasupuleti et al. [28] showed that the Liver with nanozinc oxide at dose of $2000 \mathrm{mg} / \mathrm{kg} \mathrm{B.W}$. appears focal necrosis of liver. Esmaeillou et al. [29] showed the histopathology changes of liver with nanozinc oxide, such as cellular necrosis, congestion, and glycogen accumulation in liver.

4.2.2. Kidneys. Wang et al. [27] reported that the histopathology changes of kidneys in the female mice are shown in the $80 \mathrm{~nm} \mathrm{TiO}_{2}$ group; the renal tubule was filled with the proteinic liquids. In addition, the serious swelling in the renal glomerulus was observed in the group treated with fine particles. Esmaeillou et al. [29] reported that the rats' group exposure to nanozinc oxide explained swelling in epithelial cells of proximal tubules, glomeruli segmentation, hydropic degeneration in kidneys' epithelial cells, and necrosis of epithelial cells in kidney tubules. The previous study had agreement with the results in this research.

4.2.3. Lung. Histopathology, examined sections of lung of rat treated with both magnetite and folate- coated magnetite had different changes (Figures 25, 26, 27, 28, 29, and 30). Esmaeillou et al. [29] indicated that rats group after exposure to nanozinc oxide showed the histopathology changes of lung like this serous inflammation, severe hyperemia in alveoli, and edema in lung. Warheit et al. [30] administrated that the size range $<100 \mathrm{~nm}$ of a-quartz particles produce more potent inflammatory responses when compared to larger particles of similar chemistry at the same mass concentrations or doses particles in rats: toxicity is not dependent upon particle size but on surface characteristics.

4.2.4. Spleen. Interestingly, trace damage of reproductive organs was detected in further histopathology examinations. The atretic/healthy follicle ratio was significantly higher in examined sections of treated mice spleen compared with control group. The possible mechanism through which $\mathrm{ZnO}$ nanoparticles exert their toxic effects on human liver cells was investigated by Sharma et al. [31]. The results demonstrate that $\mathrm{ZnO}$ nanoparticles accumulate in the tissues and induce intracellular reactive oxygen species (ROS) generation. ROS trigger a decrease in mitochondrial membrane potential (MMP) with a simultaneous increase in the ratio of $\mathrm{Bax} / \mathrm{Bcl} 2$ leading to mitochondrial mediated apoptosis. Moreover, ROS can also induce DNA damage. It seems that 
different nanoparticles exert their toxic effects on different tissues through similar oxidative mechanisms, this result is consistent with the group fed standard diet and three doses of magnetite while disagree with other groups.

\section{Conclusion}

Different studies on the toxicological effects of nanoparticles have indicated that these particles act with the similar oxidative toxicological mechanisms and these effects are dependent on their physicochemical properties such as specific surface area, the properties of the metal concerned, as well as nanoparticle size. Furthermore, different exposure routes, such as oral administration, dermal contact, and inhalation, have various specific toxicological impacts. Symptoms of vomiting, loss of appetite, and severe lethargy demonstrate that magnetite and folate-coated magnetite nanoparticles have serious toxicological effects in vivo. The biochemical and pathological examinations revealed that lung, liver, and kidney are target organs for these particles. According to the present results, magnetite and folate-coated magnetite nanoparticles can induce their toxicological effects on different organs and some parameter of blood picture within a 3week timeframe in the rats. Therefore, it is necessary for all researchers who are regularly exposed to nanoparticles such as these nanoparticles to consider the toxicological hazards especially the size of $54 \mathrm{~nm}$.

\section{Conflict of Interests}

The authors declare that there is no conflict of interests regarding the publication of this paper.

\section{Acknowledgments}

The author would like to thank Professor Sahar Zaghloul (Chair Department of Nutrition Requirements and GrowthNational Nutrition Institute) for her aid in writing and correcting of the language in this paper.

\section{References}

[1] House of Lords Science and Technology Committee (HLSTC), Nanotechnologies and Food, The Authority of the House of Lords, The Stationery Office, London, UK, 2010.

[2] H. Chen, J. Weiss, and F. Shahidi, "Nanotechnology in nutraceuticals and functional foods," Food Technology, vol. 60, no. 3, pp. 30-36, 2006.

[3] J. Weiss, P. Takhistov, and D. J. McClements, "Functional materials in food nanotechnology," Journal of Food Science, vol. 71, no. 9, pp. R107-R116, 2006.

[4] H. Bouwmeester, S. Dekkers, M. Noordam et al., "Health impact of nanotechnologies in food production," Health risks of application of nanotechnologies and nanoparticles within the food 772.308.01, RIKILT and RIVMH, pp. 9-10, 2007.

[5] G. Miller, R. Senjen, P. Cameron et al., "Nanotechnology and the environment: the nano-atomic reconstruction of nature," Chain Reaction, vol. 97, pp. 23-26, 2008, http://nano.foe.org.au/ node/130.
[6] P. G. Brady, "Iron deficiency anemia: a call for aggressive diagnostic evaluation," Southern Medical Journal, vol. 100, no. 10, pp. 966-967, 2007.

[7] Centers for Disease Control and Prevention (CDC), "Recommendations to prevent and control iron deficiency in the United States (1998)," Morbidity and Mortality Weekly Report, vol. 47, pp. 1-29, 2007.

[8] R. Hoffman, E. Benz, S. Shattil et al., "Disorders of iron metabolism: iron deficiency and overload," in Hematology, chapter 26, Churchill Livingstone, Philadelphia, Pa, USA; Harcourt Brace \& Co, New York, NY, USA, 3rd edition, 2000.

[9] W. Shang, J. H. Nuffer, V. A. Muñiz-Papandrea, W. Colón, R. W. Siegel, and J. S. Dordick, "Cytochrome c on silica nanoparticles: influence of nanoparticle size on protein structure, stability, and activity," Small, vol. 5, no. 4, pp. 470-476, 2009.

[10] V. Hoffart, A. Lamprecht, P. Maincent, T. Lecompte, C. Vigneron, and N. Ubrich, "Oral bioavailability of a low molecular weight heparin using a polymeric delivery system," Journal of Controlled Release, vol. 113, no. 1, pp. 38-42, 2006.

[11] A. Nel, T. Xia, L. Mädler, and N. Li, “Toxic potential of materials at the nanolevel," Science, vol. 311, no. 5761, pp. 622-627, 2006.

[12] Y. J. Hao, G. Q. Jin, X. D. Han, and X. Y. Guo, "Synthesis and characterizationof bamboo-like $\mathrm{SiC}$ nanofibers," Materials Letters, vol. 60, no. 11, pp. 1334-1337, 2006.

[13] B. K. Oh, M. E. Robbins, B. J. Nablo, and M. H. Schoenfisch, "Miniaturized glucose biosensor modified with a nitric oxidereleasing xerogel microarray," Biosensors and Bioelectronics, vol. 21, no. 5, pp. 749-757, 2005.

[14] P. G. Reeves, F. H. Nielsen, and G. C. Fahey Jr., "AIN-93 purified diets for laboratory rodents: final report of the American Institute of Nutrition ad hoc writing committee on the reformulation of the AIN-76A rodent diet," Journal of Nutrition, vol. 123, no. 11, pp. 1939-1951, 1993.

[15] D. M. Hegested, R. C. Mills, C. A. Elvehjer, and E. B. Hart, "Choline in chicks," The Journal of Biological Chemistry, vol. 138, pp. 459-466, 1941.

[16] J. A. Campbell, "Methodology of protein evaluation," PAG. Nutr. Document R. 101 Add. 37, June, Meeting, New York, NY, USA, 1963

[17] D. Bancroft, A. Stevens, and R. Turner, Theory and Practice of Histological Techniques, Churchill Livingstone, London, UK, 4th edition, 1996.

[18] N. Singha, G. J. S. Jenkins, R. Asadi, and S. H. Doak, "Potential toxicity of superparamagnetic iron oxide nanoparticles (SPION)," Nano Reviews, vol. 1, p. 5358, 2010.

[19] D. Fischer, Y. Li, B. Ahlemeyer, J. Krieglstein, and T. Kissel, "In vitro cytotoxicity testing of polycations: influence of polymer structure on cell viability and hemolysis," Biomaterials, vol. 24, no. 7, pp. 1121-1131, 2003.

[20] S. J. H. Soenen, J. Baert, and M. De Cuyper, “Optimal conditions for labelling of 3T3 fibroblasts with magnetoliposomes without affecting cellular viability," ChemBioChem, vol. 8, no. 17, pp. 2067-2077, 2007.

[21] American Association for Clinical Chemistry, "The complete blood count $(\mathrm{CBC})$ is often used as a broad screening test to determine an individual's general health status," 2012.

[22] D. Huang, J. Hsiao, Y. Chen et al., "The promotion of human mesenchymal stem cell proliferation by superparamagnetic iron oxide nanoparticles," Biomaterials, vol. 30, no. 22, pp. 36453651, 2009. 
[23] N. Sadeghiani, L. S. Barbosa, L. P. Silva, R. B. Azevedo, P. C. Morais, and Z. G. M. Lacava, "Genotoxicity and inflammatory investigation in mice treated with magnetite nanoparticles surface coated with polyaspartic acid," Journal of Magnetism and Magnetic Materials, vol. 289, pp. 466-468, 2005.

[24] M. N. N. Vieira, J. D. Figueroa-Villar, M. N. L. Meirelles, S. T. Ferreira, and F. G. De Felice, "Small molecule inhibitors of lysozyme amyloid aggregation," Cell Biochemistry and Biophysics, vol. 44, no. 3, pp. 549-553, 2006.

[25] U. O. Häfeli, J. S. Riffle, L. Harris-Shekhawat et al., "Cell uptake and in vitro toxicity of magnetic nanoparticles suitable for drug delivery," Molecular Pharmaceutics, vol. 6, no. 5, pp. 1417-1428, 2009.

[26] J. Buscombe, G. Paganelli, Z. E. Burak et al., "Sentinel node in breast cancer procedural guidelines," European Journal of Nuclear Medicine and Molecular Imaging, vol. 34, no. 12, pp. 2154-2159, 2007.

[27] B. Wang, W. Feng, M. Wang et al., "Acute toxicological impact of nano- and submicro-scaled zinc oxide powder on healthy adult mice," Journal of Nanoparticle Research, vol. 10, no. 2, pp. 263276, 2008.

[28] S. Pasupuleti, S. Alapati, S. Ganapathy, G. Anumolu, N. R. Pully, and B. M. Prakhya, "Toxicity of zinc oxide nanoparticles through oral route," Toxicology and Industrial Health, vol. 28, no. 8, pp. 675-686, 2012.

[29] M. Esmaeillou, M. Moharamnejad, R. Hsankhani, A. A. Tehrani, and H. Maadi, "Toxicity of $\mathrm{ZnO}$ nanoparticles in healthy adult mice," Environmental Toxicology and Pharmacology, vol. 35, no. 1, pp. 67-71, 2013.

[30] D. B. Warheit, T. R. Webb, V. L. Colvin, K. L. Reed, and C. M. Sayes, "Pulmonary bioassay studies with nanoscale and finequartz particles in rats: toxicity is not dependent upon particle size but on surface characteristics," Toxicological Sciences, vol. 95, no. 1, pp. 270-280, 2007.

[31] V. Sharma, P. Singh, A. K. Pandey, and A. Dhawan, "Induction of oxidative stress, DNA damage and apoptosis in mouse liver after sub-acute oral exposure to zinc oxide nanoparticles," Mutation Research, vol. 745, no. 1-2, pp. 84-91, 2012. 

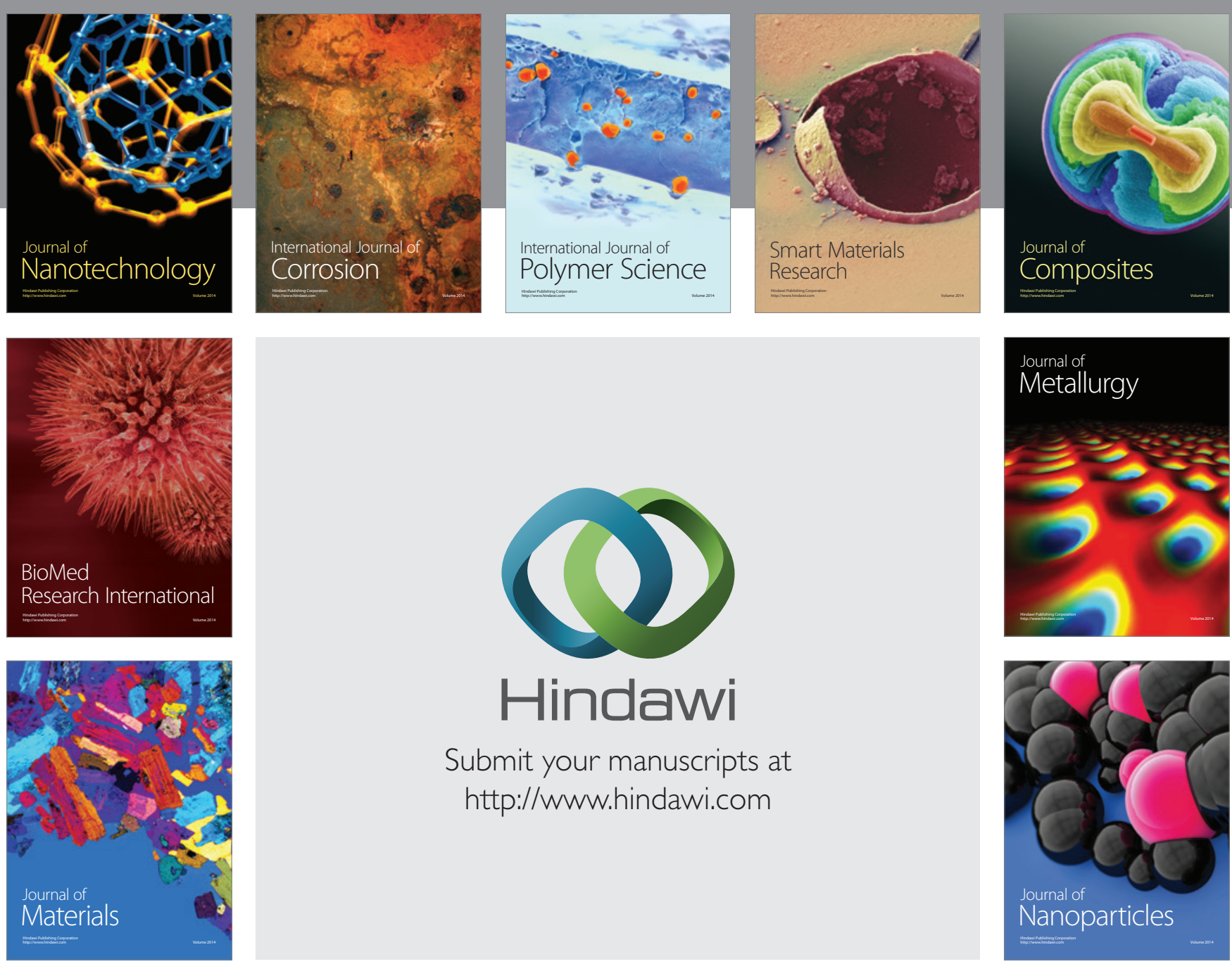

Submit your manuscripts at http://www.hindawi.com
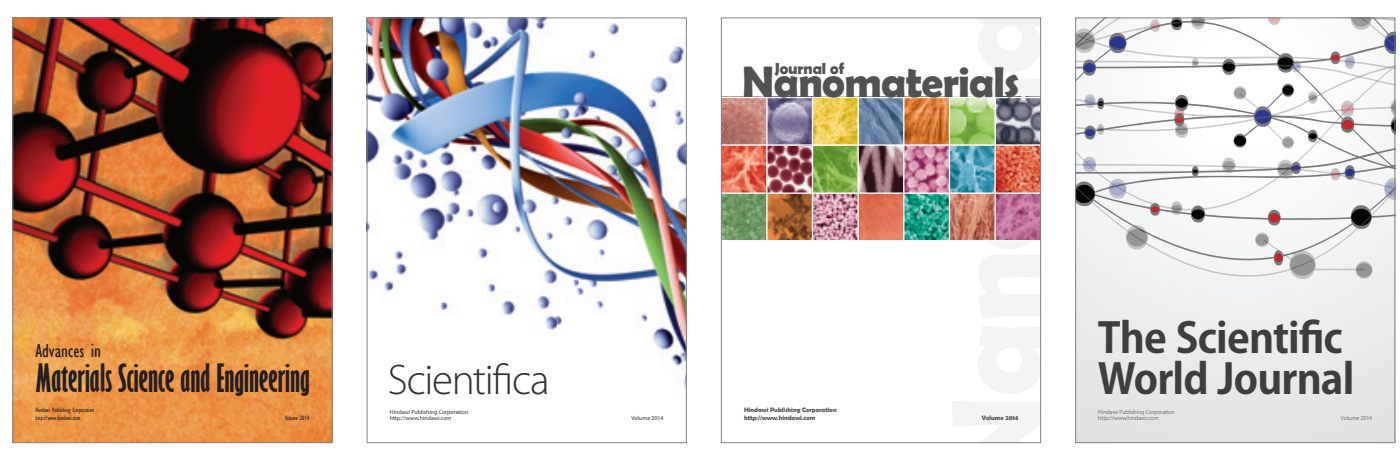

\section{The Scientific World Journal}
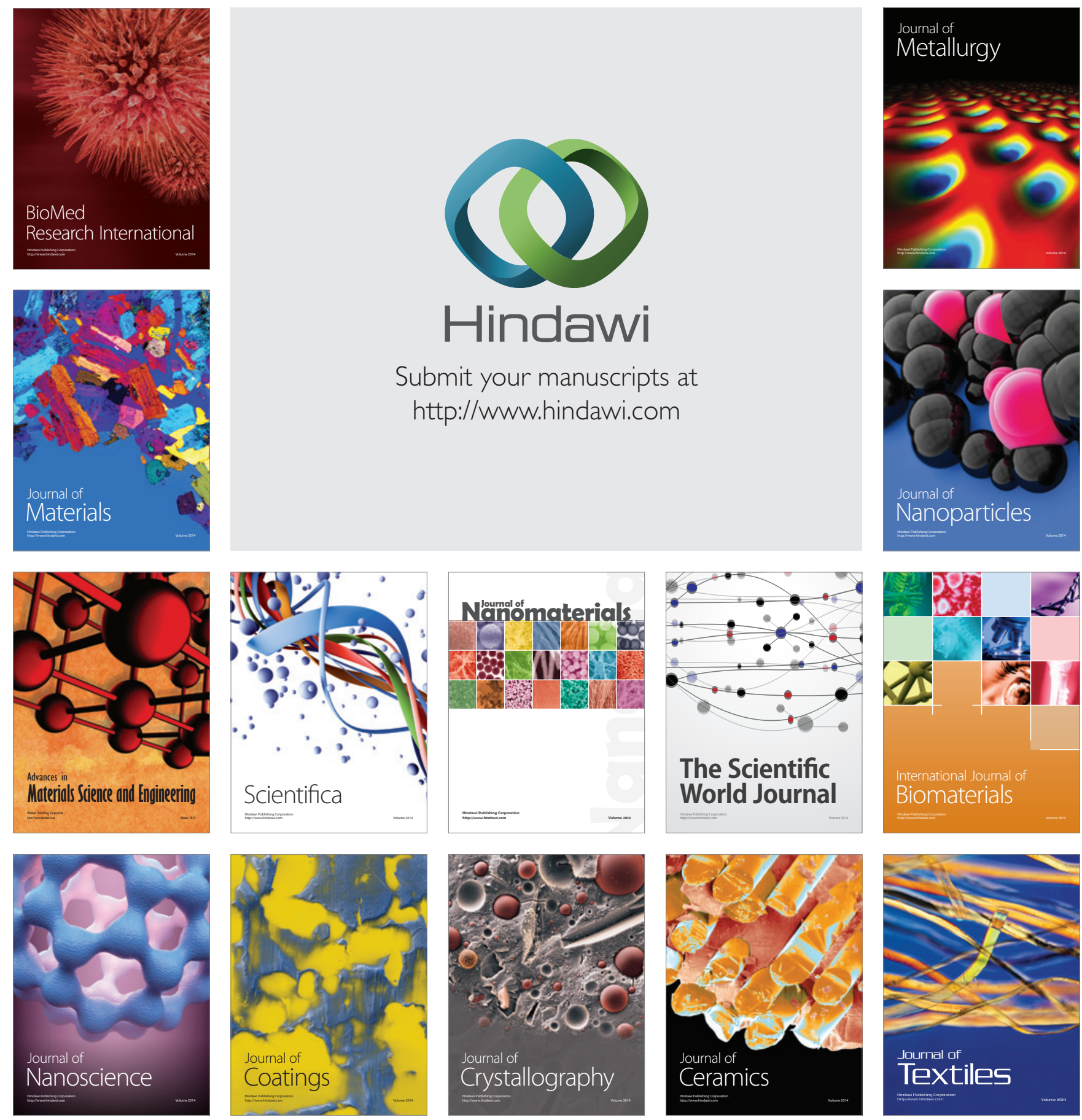